\title{
Doing gender in the context of telenursing: Analyses of authentic calls to a telenursing site in Sweden
}

\author{
Roya Hakimnia ${ }^{1}$, Marianne Carlsson ${ }^{2,3}$, Anna T. Höglund ${ }^{4}$, Inger K. Holmström *1,5 \\ ${ }^{1}$ Department of Public Health and Caring Sciences, Health Services Research, Uppsala University, Sweden \\ ${ }^{2}$ Department of Public Health and Caring Sciences, Caring Sciences, Uppsala University, Sweden \\ ${ }^{3}$ Department of Health and Caring Sciences, University of Gävle, Sweden \\ ${ }^{4}$ Department of Public Health and Caring Sciences, Centre for Research Ethics \& Bioethics, Uppsala University, Sweden \\ ${ }^{5}$ School of Health, Care and Social Welfare, Division of Caring Sciences, Västerås, Sweden
}

Received: February 12, 2014

DOI: $10.5430 /$ cns.v3n2p24
Accepted: November 6, $2014 \quad$ Online Published: December 18, 2014

URL: http://dx.doi.org/10.5430/cns.v3n2p24

\begin{abstract}
Introduction: Aim: The aim of the present study was to analyze authentic health calls to a telenursing site in Sweden regarding reasons for calling and outcome of the calls with focus on a gender perspective. Background: Telephone advice nursing is an expanding service in many Western countries. In Sweden, all regions are now connected to a national telenursing service. Healthcare in Sweden is stipulated by law to be equitable. This includes the teleursing service, which is a new actor in Swedish healthcare system, and which often is a citizen's first contact with healthcare.
\end{abstract}

Methods: The study had a descriptive and comparative design. 800 authentic calls to SHD were analysed regarding reasons for calling, and outcome of the calls.

Results: The results showed that men, and especially fathers, received more referrals to general practitioners than women. The most common caller was a woman fluent in Swedish (64\%), and the least likely caller was a man non-fluent in Swedish (3\%). All in all, $70 \%$ of the callers were women. When the calls concerned children, $78 \%$ of the callers were female. In total, $9 \%$ of the calls were made by a man calling for another person. Callers were predominately young (mean age 29 years for women and 33 for men).

Conclusions: It is important that telenursing does not become a "feminine" activity, only suitable for young callers fluent in Swedish. Given the telenurses' gatekeeping role, there is a risk that differences on this first level of health care can be reproduced throughout the whole healthcare system. In striving for more equitable telenursing services, future research might investigate if campaigns encouraging men to call, and more frequent use of translators could enhance access to telenursing services.

Key Words: Telenursing, Gender, Sweden, Hegemonic masculinity, Ideal femininity, Authentic health calls

\section{Introduction}

National telephone help-lines have been developed in several Western countries; for example, in the US and in the
UK. ${ }^{[1]}$ In Sweden, Swedish Healthcare Direct (SHD) was launched in 2003 and in 2013 all 21 counties are connected to the service. Telenurses play an important role in steering

\footnotetext{
*Correspondence: Inger K. Holmström; Email: inger.holmstrom@mdh.se; Address: School of Health, Care and Social Welfare, Division of Caring Sciences, Västerås, Sweden.
} 
the patient to the right level of health care, which is supposed to have both financial and health advantages. ${ }^{[2]}$

Approximately 6 million calls are made to SHD every year, and calling SHD is often the first contact with healthcare for citizens in situations where they experiece health-related problems and symptoms. One of the goals of telenursing services is to use resources effectively, and steer the flow of patients to an optimal level of care. In this manner gatekeeping becomes an important function for telenurses. During a normal workday, a telenurse in Sweden handles between six and eight calls per hour, resulting in up to approximately 60 calls a day. ${ }^{[3]}$ The outcome of the call could be self-care advice, referral to a general practitioner (GP) or referral to the emergency room, and in some counties the telenurse is also able to directly book an appointment with a GP on call. The telenurses are obliged to keep written records of every patient they advise. However, they do not have access to a caller's previous medical records, medical history or medication list. In 2003, a computerized decision support program was introduced, which, since 2013 , is compulsory. The nurses use headsets and computers, while sitting in an office landscape with their colleagues. In many ways, the working context is similar to that of a typical call center in a private company. ${ }^{[2]}$

\subsection{Background}

The majority of telenurses are women, as $90 \%$ of the Swedish nursing force consists of women, ${ }^{[4]}$ and international studies have reported that women call telenurses more often than men. ${ }^{[5,6]}$ Furthermore, it has been reported that telenurses encounter gender-related issues in their daily work. In a study by Höglund and Holmström, ${ }^{[7]}$ telenurses described how they identified two categories of male callers, namely, the assertive versus the reluctant man. Female callers were described as worried, upset, and easier to persuade to wait and see, rather than seeking further health care. Likewise, a Swedish study on paediatric calls showed that fathers were more often referred to healthcare services, while mothers were more likely to receive self-care advice $^{[8]}$ when calling for childern with similar symptoms. Hence, aspects other than the child's condition could affect the outcome of the call. This might jeoparize both patientsafety and access to equal care for all citizens, the latter being stipulated by Swedish Health and Medical Services Act (1982:763).

One hypotheis is that parental gender norms might be such an influential aspect. A well-established definition of gender states that it is a social and constructive process, beyond biology. West and Zimmerman ${ }^{[9]}$ argue that we are continuously "doing gender". Hence, gender is not a fixed reality, but something constructed by individuals and the structures of politics and economics in a society. Performance of care has been identified as one of the main characteristics of womanhood, ${ }^{[10]}$ whilst the most embraced masculinity is based on dominance over women, which Connell ${ }^{[11]}$ defines as "hegemonic masculinity". Hegemonic masculinity is normative rather than normal; even though few people might live up to these idealized pictures, all men are required to position themselves in relation to them. ${ }^{[11,12]}$ In analogy with Connell, Schipper ${ }^{[13]}$ identified a "hegemonic femininity", i.e., a femininity that guarantees the dominant position of men and the subordination of women.

Health is an important arena where gender is constructed. Men can use health beliefs to demonstrate power, dominance and hegemonic masculinity. ${ }^{[14-16]}$ According to Saltonstall, ${ }^{[17]}$ "doing health" is a form of "doing gender". Risk-taking and refraining from seeking health care, excessive drinking and other health-damaging behaviors are associated with hegemonic masculinity, and are believed to contribute to men's higher mortality in most Western countries. $^{[14-16]}$

It has also been reported that gender interact (or intersect) with other categories, such as age and ethnicity in people's health behaviour. For example, studies on NHS Direct in the $\mathrm{UK}^{[18,19]}$ have indicated that migrants use this service less. Sweden has for several decades been a multicultural society. Presently, over $15 \%$ of the citizens are born abroad (migrationsinfo.se). According to the Swedish Health and Medical Services Act (1982:763), all healthcare in Sweden should be equitable for all citizens, regardless of age, gender and ethnicity. This includes the national telenursing service, with its' important gatekeeping function. Our previous research has shown that there are gender differences in outcomes of paediatric calls which could not be explained by differences in symptom severity. ${ }^{[8]}$ From the perspective of patient safety and equitable healthcare, it is thus important to study if these patterns can be found as well in larger samples of adult callers.

\subsection{Aim}

The aim of the present study was to analyse authentic health calls to a telenursing site in Sweden regarding reasons for calling and outcome of the calls from a gender perspective. Central research questions were: (1) who is calling, (2) who are they calling for, (3) what are the reasons for calling, and (4) what is the outcome of the call?

\section{Methods}

\subsection{Design}

The study had a descriptive and comparative design.

\subsection{Sample and setting}

After statistical considerations 800 calls, chosen randomly from 5,000 recorded calls, were analyzed. All chosen calls contained an outcome, such as self-care advice or a referral. 


\subsection{Data collection}

The calls were recorded at a telenursing call center site in central Sweden that handled about 100,000 calls per year. Data were collected over a period of 11 months during 2004/2005. Callers were informed about the ongoing study in a prerecorded message when they called the telenursing site. They consented to participating in the study in an active way by entering a certain number on the telephone. The nurses were informed verbally about the study, and 11 out of 20 nurses (all female) consented to participate.

\subsection{Data analysis}

The calls were analyzed directly from the recordings. A matrix was developed, where the caller's gender, age and fluency or non-fluency in Swedish were noted. For gender there were three options: female, male and other. The third alternative was used when the caller's gender could not be assessed or when the caller did not want to be defined as either man or woman. The fluency or non-fluency in Swedish was assessed by the researcher in a subjective manner by listening to understanding or describing problems related to language skills. In another box it was marked for whom the call was made, e.g., if an adult was calling for a child or for him/herself. The reason the caller contacted the telenurse was noted, as well as the length of the call. Finally, the outcome of the call was noted: self-care advice, booking an appointment for a GP on call, referral to a GP, referral to other health care services, referral to the emergency room or providing other information (for example, opening hours).

The calls were analyzed by IBM SPSS (Statistical Product and Service Solutions) 19.0, using Chi2 tests for categorical data on gender and outcome and reason for calling. Odds ratio (OR) was calculated for outcome. Age and fluency or non-fluency in Swedish were analyzed descriptively.

\subsection{Ethical considerations}

The study was approved by the Regional Ethics Review Board. No benefits were gained from participating in the study; the same service was given to all callers during this period. Telenurses and callers were included after informed consent and were able to end their participation in the project at any time. The results are presented in a way that guarantees all participants' confidentiality.

\section{Results}

\subsection{Who is calling?}

The majority of the calls (70\%) were performed by women, and this pattern was similar in both language groups. The total percentage of callers who were non-fluent in Swedish in the sample was $6 \%$ for women and $3 \%$ for men. Five callers could not be identified as either man or woman (see Table 1). The mean age of the female patients was 29 years and the mean age of the male patients was 33 years.

Table 1: Ethnicity/language proficiency and gender of the caller

\begin{tabular}{|c|c|c|c|c|c|c|c|c|c|}
\hline \multirow[b]{2}{*}{ Language } & \multicolumn{3}{|c|}{ Women } & \multicolumn{3}{|c|}{ Men } & \multicolumn{3}{|c|}{ Other } \\
\hline & $\mathbf{n}$ & $\begin{array}{l}\text { \% of total } \\
\text { calls }\end{array}$ & $\begin{array}{l}\text { \% of calls in } \\
\text { language group }\end{array}$ & $\mathbf{n}$ & $\begin{array}{l}\text { \% of total } \\
\text { calls }\end{array}$ & $\begin{array}{l}\text { \% of calls in } \\
\text { language group }\end{array}$ & $\mathbf{n}$ & $\begin{array}{l}\% \text { of total } \\
\text { calls }\end{array}$ & $\begin{array}{l}\% \text { of calls in } \\
\text { language group }\end{array}$ \\
\hline Fluent in Swedish & 510 & 64 & 70 & 214 & 27 & 29 & 4 & 0.5 & 0.5 \\
\hline Not fluent in Swedish & 49 & 6 & 68 & 22 & 3 & 30 & 1 & 0.1 & 1 \\
\hline
\end{tabular}

\subsection{Who are they calling for?}

The callers called for themselves, children or other adults. In all groups women were in the majority of those making the calls, and the highest proportion was in the group calling for children $(p=.003) ; 77 \%$ and $87 \%$ respectively in the different language groups. The lowest proportion of female callers was found in the group of people calling for themselves $(p=.005) ; 61 \%$ and $67 \%$ respectively in the different language groups. Calls made for oneself were the most common form in all language groups irrespective of gender, but men called more for themselves per percentage and less for others, especially concerning children (see Table 2). No significant differences for calling for other adults $(p=$ .8) were found. Adding the calls together, the likelihood of finding a man calling for another person in our sample was $9 \%$. The corresponding number for female callers was
$28.5 \%$.

\subsection{What are the reasons for calling?}

Symptoms from the airways and ears were the main reasons for calling in most groups. Other common reasons were skin issues and symptoms in the abdomen for both men and women, fluent or non-fluent in Swedish. More men called to get information only (see Table 3).

\subsection{What are the outcomes of the calls?}

When the outcomes of the calls were divided on gender and reasons for calling, significant gender differences were found for receiving referral to a $G P(O R=2.54)$. Comparing parents, it was shown that fathers were referred to a GP to a greater extent $(\mathrm{OR}=5.7)$ than mothers were (see Table 4). 
Table 2: For whom the caller calls, divided on ethnicity/language proficiency and gender

\begin{tabular}{|c|c|c|c|c|c|c|c|}
\hline \multirow{2}{*}{ Language } & \multirow{2}{*}{ Calling for } & \multicolumn{2}{|c|}{ Women } & \multicolumn{2}{|c|}{ Men } & \multicolumn{2}{|c|}{ Other } \\
\hline & & $\mathbf{n}$ & $\%$ & $\mathbf{n}$ & $\%$ & $\mathbf{n}$ & $\%$ \\
\hline \multirow{3}{*}{ Fluent in Swedish } & Themselves & 309 & 67 & 150 & 32 & 3 & 1 \\
\hline & Children & 156 & 77 & 48 & 23 & - & - \\
\hline & Other adults & 45 & 72 & 16 & 26 & 1 & 2 \\
\hline \multirow{3}{*}{ Not fluent in Swedish } & Themselves & 23 & 61 & 15 & 39 & - & - \\
\hline & Children & 20 & 87 & 3 & 13 & - & - \\
\hline & Other adults & 6 & 55 & 4 & 36 & 1 & 9 \\
\hline
\end{tabular}

Table 3: Reasons for calling, divided on ethnicity/language proficiency and gender

\begin{tabular}{lllllll}
\hline Language & Women & $\mathbf{\%}$ & Men & \% & Other & \% \\
\hline \multirow{5}{*}{ Fluent in Swedish } & Airways and ears & 29 & Airways and ears & 29 & Information & Airways and ears \\
& Skin & 14 & Skin & 20 & \\
& Abdomen & 9 & Information & 12 & \\
& Urinary tract & 8 & Abdomen & 10 & \\
& Information & 8 & Back and limbs & 7 & \multirow{2}{*}{ Back and limbs } \\
& Airways and ears & 41 & General illness & 18 & \\
& Abdomen & 12 & Back and limbs & 18 & \\
\end{tabular}

Divided on outcome, language and gender, no significant in the whole sample was 4 minutes and 30 seconds $(\mathrm{SD}=$ differences were found in the material. The most common 2.6); for men the mean call length was 4 minutes (SD =2.6) caller was a woman fluent in Swedish. The mean call length and for women it was 4 minutes and 40 seconds $(\mathrm{SD}=2.6)$.

Table 4: Outcome of the calls divided on for whom the call was made and the gender of the caller

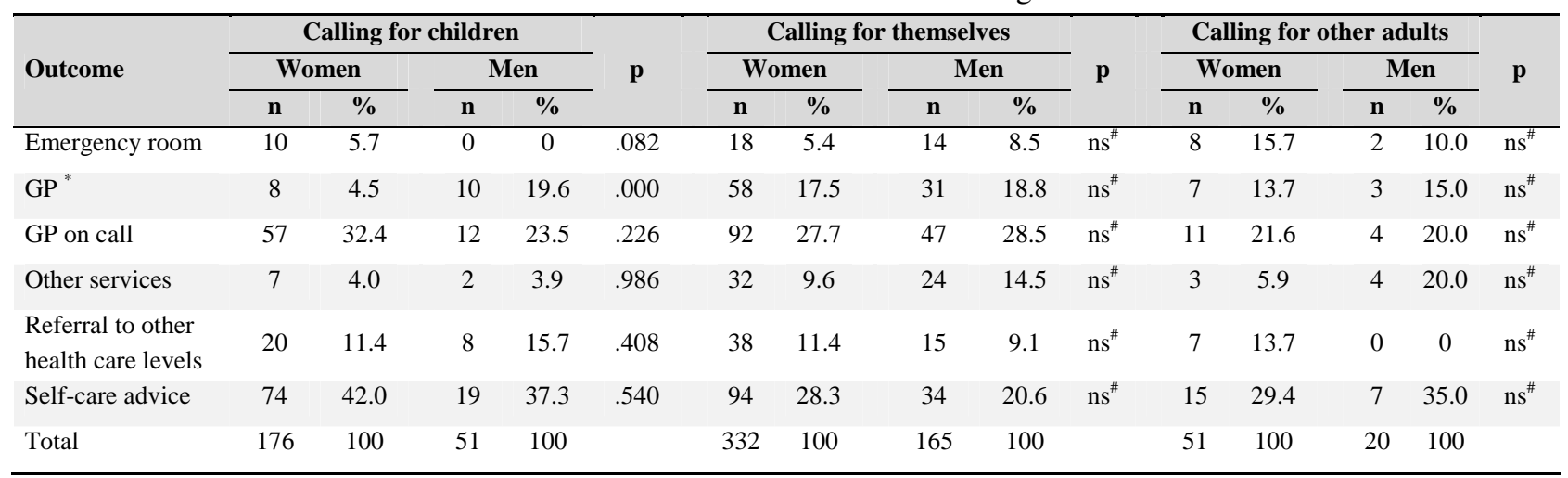

${ }^{*}$ General practitioner

" Non-significant

\section{Discussion}

Differences were found in this study concerning who is calling, for whom they are calling, and the advice the callers received from the telenurses. It is well known that women generally seek healthcare more frequently. ${ }^{[17,20]}$ The same pattern was found also in the present study, as the majority of callers were women, and when calling for chil-

Published by Sciedu Press dren the proportion of female callers increased. In light of gender theory, this pattern can be understood as the performance of ideal ${ }^{[10]}$ or hegemonic ${ }^{[13]}$ femininity as well as of hegemonic masculinity. ${ }^{[11,14]}$ Calling telenurses, for oneself or for others, can be in line with ideal femininity, which is linked to attending self-care, seeking professional health care advice and performing care for others. More- 
over, physical vulnerability, weakness, and compliance have been identified as features of ideal femininity. ${ }^{[10]}$ Correspondingly, men can enact hegemonic masculinity through refraining from seeking healthcare ${ }^{[14-16]}$ in this case refraining from calling a telenurse.

It was significantly more common for women to call on behalf of someone else than men. The likelihood of finding a man calling for another person in our sample was only $9 \%$. The corresponding number for female callers was $28.5 \%$. These findings are concurrent with previous studies, ${ }^{[8]}$ and underscore the female role of being the primary carer in families. A recent study suggested that "surrogate calls" (calls made on behalf of someone else) made by women for men could increase men's medical access. ${ }^{[21]}$

A striking finding in our study was that men received more GP referrals than women did, especially concerning fathers as compared to mothers. This is in line with the findings of Kaminsky, et al., ${ }^{[8]}$ where fathers were found to receive healthcare referrals to a significantly higher extent than mothers, although there were no indications that the fathers called for more emergency situations or other differences in the severity of the child's symptoms. This is in line with gender theories arguing that parenting is an important arena for doing gender. ${ }^{[22]}$ Arguably, the telenurses saw the mothers as the more "essential" parents. ${ }^{[23]}$ This has also been stated by telenurses themselves in a previous interview study. ${ }^{[7]}$ This pattern may also reflect the norm of hegemonic cultural ideals of masculinity, which clashes with being an involved father. ${ }^{[11]}$ The societal gender order has also been shown to be mirrored in calls to SHD, as representations of the reluctant male caller and the ideal feminine caller were identified by discourse analysis of authentic calls. $^{[24]}$

As for the actual calls, the mean call length in the whole study sample was 4 minutes and 30 seconds. For men, the mean call length was 4 minutes, and for women 4 minutes and 40 seconds, as previously mentioned. We have however not studied the causes for this difference. One might speculate that as women receive more self-care advice, the provision of such advice might take more time for the telenurse to pass on. This is, however, only one possible explanation for this finding.

That men use health care to a lesser extent than women has previously been pointed out. ${ }^{[20]}$ From a biomedical perspective one could argue that the illness and sickness women face ${ }^{[25]}$ could lead to a greater need to call telenurses. Hence, an important question that our findings raise is what an appropriate use of telenursing services would be. Do men call too little, or is it women who call too much? What is the norm in the context of seeking health care? The literature tends to focus on the "overutilization" of healthcare by women and sees this as a problem. ${ }^{[15]}$ Against this, one could argue that men "underutilize" healthcare services such as telenursing, considering their actual needs.

The fact that $15 \%$ of the current population in Sweden is foreign born, and the total percentage of callers non-fluent in Swedish in the study sample was $9 \%$ (6\% for women and $3 \%$ for men) suggests that non-fluent speakers call less frequently. This parallels results from the UK regarding NHS Direct, ${ }^{[18,19]}$ indicating that migrants use this service less. Our study has also shown that the patients who turned to the telenursing services were predominately young (mean age for women 29 years and for men 33 years). To make the service accessible and equal for all citizens, efforts might be needed to reach out to elderly persons, who are perhaps more likely to have health-related problems, and to immigrants.

\section{Strengths and limitations}

Although this study was designed from a gender perspective, age and language proficiency were also analysed. Using language as a proxy for ethnicity has the advantage of being the way ethnicity is perceived by, and presented to the telenurses. The disadvantage is that it is subjective, relying on the researcher's judgment. Other weaknesses include that we have only had access to data regarding the outcome of the call per se (self-care advice/referral/GP/emergency room), and not the eventual outcome in relation to health. As we were not granted ethical permission to study the patients' records, such data were unavailable.

The large data set of authentic calls can be looked upon as a strength. The present authors have different professional backgrounds, with the last author having own experiences of working as a telenurse. This means that the authors could take on both an emic and an etic perspective, which also is a strength.

Although data were collected some years ago, the gender system in the Swedish society has not changed since the data collection took place. As more recent investigations show a similar amount of male and female callers to SHD, ${ }^{[8]}$ it is reasonable to believe that the results are applicable on the current societal situation. Hence, we argue that much can be learned from this study concerning telenursing in Sweden, and similar countries today.

\section{Conclusion and practical implications}

In the context of telenursing, callers and nurses are "doing health" and "doing gender" simultaneously. It is important to stress that both callers and telenurses participate in "doing gender"; callers by gendered calling patterns, and telenurses by giving different advice. By not calling, men may construct hegemonic masculinity, and by calling, women can act in line with ideal femininity. When calling for children, mothers might reinforce the picture of the woman being the primary parent. Calling a telenurse also appears to require 
fluency in the language, as non-fluent speakers appeared to call less frequently. It might also be that when being new in Sweden, they did not know about this service.

Given the telenurses' gatekeeping role, there is a risk that these differences on the first level of healthcare are reproduced throughout the whole health care system. At the same time, telenursing services have the potential to increase access to health care, preventive care and patient involvement at an early stage. All these aspects could contribute to decreasing inequity in health by reaching out to groups that have been shown to underutilize health care.

Since equitable healthcare is stipulated by the Swedish Health and Medical Services Act (1982:763), it is important that telenursing does not become a "feminine" task, mainly performed by female nurses and used by female callers and/or a service only suitable for callers who are fluent in one dominant language. Further research is needed on how to enhance a more equitable use of telenursing services, which can in turn increase equitable access to other healthcare services. It is possible that campaigns encouraging men to call, and a more frequent use of translators, could make telenursing more accessible to groups who currently appear to use the services to a lesser extent.

\section{Acknowledgements}

Authors' contributions: RH conducted the data analysis and drafted the manuscript. MC designed the study, provided statistical expertise and gave valuable contributions to the drafting of the manuscript. ATH designed the study, provided expertise knowledge in gender studies and gave valuable contributions to the drafting of the manuscript. IKH designed the study, obtained funding, provided expertise knowledge in telenursing, co-analysed the data and drafted the final version of the manuscript.

We are indebted to the participating telenurses and callers. We also wish to thank the Swedish Research Council and the Faculty of Medicine, Uppsala University for funding.

\section{References}

[1] Collett A, Kent W, Swain S. The role of a telephone helpline in provision of patient information. Nurs Stand. 2006; 20: 4144. PMid:16674000. http://dx.doi.org/10.7748/ns2006.04 $.20 .32 .41 . c 4125$

[2] Andersson Bäck M. Conceptions, Conflicts and Contradictions in the Introduction of a Swedish Health Call Centre. Dissertation from the Faculty of Education, Department of Work Science. University of Gothenburg: Gothenburg; 2008.

[3] Swedin B. Vårdråd direkt, sjukvårdsrådgivningar i samverkan. Slutrapport från Utredningen om nationellt samordnad sjukvårdsrådgivning. (Final report investigating Swedish Health Care Direct). Landstingförbundet: Stockholm; 2003.

[4] Östlin P. Gender inequalities in health: The significance of work. In Gender and Social Inequalities in Health. (Wamala SP and Lynch J eds.) Studentlitteratur: Lund; 2002. 43-65p.

[5] Goode J, Hanlon G, Luff D, O'Cathain A, Strangleman T, Greatbatch D. Male callers to NHS Direct: The assertive carer, the new dad and the reluctant patient. Health. 2004; 8: 311-328. PMid: 15200758 .

[6] Waqas U, Theivendra A, Sood V, Vasireddy A, Maryon-Davis A. Men and older people are less likely to use NHS Direct. BMJ. 2003; 326: 710. PMid:12663413. http://dx.doi.org/10.1136/bmj $.326 .7391 .710 / \mathrm{a}$

[7] Höglund AT, Holmström I. "It's easier to talk to a woman". Aspects of gender in Swedish telenursing. J Clin Nurs. 2008; 17: 2979-2986. PMid:19012768. http://dx.doi.org/10.1111 /j.1365-2702.2008.02345.x

[8] Kaminsky E, Carlsson M, Höglund AT, Holmström I. Paediatric health calls to Swedish telenurses: A descriptive study of content and outcome. J Telemed Telecare. 2010; 16: 454457. PMid:20921290. http://dx.doi.org/10.1258/jtt.201 0.100110

[9] West C, Zimmerman DH. Doing gender. Gend Soc. 1987; 1: 125 151. http://dx.doi.org/10.1177/0891243287001002002

[10] Lyons AC. Masculinities, femininities, behaviour and health. Soc Pers Psychol. 2009; 3: 394-412.

[11] Connell RW. Masculinities. 2. ed. Polity Press: Cambridge; 2005.
[12] Connell RW, Messerschmidt JW. Hegemonic masculinity. Rethinking the concept. Gend Soc. 2005; 19: 829-859. http://dx. doi.o $\mathrm{rg} / 10.1177 / 0891243205278639$

[13] Schipper M. Recovering the feminine other: Masculinity, femininity and gender hegemony. Theory Soc. 2006; 36: 85-102. http: //dx.doi.org/10.1007/s11186-007-9022-4

[14] Connell R. Gender, health and theory: Conceptualizing the issue in local and world perspective. Soc Sci Med. 2012; 74: 16751683. PMid:21764489. http://dx.doi.org/10.1016/j.socsc imed.2011.06.006

[15] Courtenay WH. Constructions of masculinity and their influence on men's well-being: A theory of gender and health. Soc Sci Med. 2000; 50: 1385-1401. http://dx.doi.org/10.1016/S0277-9 536 (99) $00390-1$

[16] Schofield T, Connell RW, Walker L, Wood JF, Butland DL. Understanding men's health illness: A gender-relations approach to policy, research and practice. J Am Coll Health. 2000; 48: 247256. PMid:10863868. http://dx.doi.org/10.1080/0744848 0009596266

[17] Saltonstall R. Healthy bodies, social bodies: Men's and women's concepts and practices of health in everyday life. Soc Sci Med. 1993; 36: 7-14. http://dx.doi.org/10.1016/0277-9536(93 ) $90300-\mathrm{S}$

[18] Knowles E, Munro J, O'Cathain A, Nicholl J. Equity of access to health care. Evidence from NHS Direct in the UK. J Telemed Telecare. 2006; 12: 262-265. PMid:16848940. http://dx.doi.org/1 $0.1258 / 135763306777889091$

[19] Shah SM, Cook DG. Socio-economic determinants of casualty and NHS Direct use. J Pub Health. 2008; 30: 75-81. PMid:18216300. http://dx.doi.org/10.1093/pubmed/fdn001

[20] Seymour-Smith S, Wetherell M, Phoenix A. "My wife ordered me to come!": A discursive analysis of doctors' and nurses' accounts of men's use of general practioners. J Health Psychol. 2002; 7: 253267. PMid:22114249. http://dx.doi.org/10.1177/1359105 302007003220

[21] North F, Muthu A, Varkey P. Differences between surrogate telephone triage calls in an adult population and self calls. J Telemed Telecare. 2011; 17: 118-122. PMid:21139014. http://dx.doi.o $\mathrm{rg} / 10.1258 / \mathrm{jtt} .2010 .100511$ 
[22] Craig L. Children and the revolution: A time-diary analysis of the impact ofmotherhood on daily workload. J Sociology. 2006; 42: 125-143. http://dx.doi.org/10.1177/1440783306064942

[23] Walzer S. Contextualizing the employment decision of new moters. Qual Sociology. 1997; 20: 211-227. http://dx.doi.org/10.10 23/A : 1024761618294

[24] Hakimnia R., Holmström IK, Carlsson M, Höglund AT. Explor- ing the communication between telenurse and caller.A critical discourse analysis. Int J Qual Stud Health and well-being. 2014 Jun 24; 9: 24255. PMid:24964860. http://dx.doi.org/10.3402/q hw.v9.24255

[25] Case A, Paxson C. Sex differences in morbidity and mortality. Demography. 2005; 42: 189-214. PMid:15986983. http://dx.doi $. \mathrm{org} / 10.1353 / \mathrm{dem} .2005 .0011$ 